\title{
Soroprevalência de anticorpos anti-Toxoplasma gondii em propriedades de agricultura familiar no munício de Realeza, estado do Paraná, Brasil
}

Alexandra Lays Petry;, Regiane Figueredo Ghisleri, Anderson Luiz Beltrame, Michel Fernando Fritz, Diego Kozerski, Lisangela Veiga Trevisan, Juliana Paula da Silva, Gustavo Lemes de Andrade, Lucas Vieira Barbosa de Queiroz, Fagner Luiz da Costa Freitas

Laboratório de Saúde Única, Universidade Federal da Fronteira Sul (UFFS), Realeza, PR, Brasil

*Autor correspondente

e-mail: alexandralays@gmail.com

\section{Resumo}

O coccídio Toxoplasma gondii é um parasito intracelular obrigatório, que tem como hospedeiros várias espécies de animais vertebrados, principalmente felinos, bovinos e o homem, ocasionando alterações neurológicas e reprodutivas, tais como: aborto, mortalidade neonatal e deformações congênitas nos diversos hospedeiros. Pelo fato da toxoplasmose ser uma enfermidade de caráter zoonótico, principalmente em imunodeprimidos, torna-se importante o diagnóstico da infecção em vacas leiteiras, principalmente, devido à possibilidade de transmissão através do leite bovino. A pesquisa avaliou a soroprevalência de anticorpos anti-T. gondii em vacas com aptidão leiteira, em fase de lactação, oriundas de 56 propriedades de agricultura familiar pertencentes ao município de Realeza/PR. 0 trabalho foi aprovado pela Comissão de Ética no Uso de Animais da Universidade Federal da Fronteira Sul, sob o protocolo 23205.004368/2016-11, sendo pesquisados 389 animais oriundos de 56 propriedades de agricultura familiar. Após a contenção do animal, realizou-se coleta de sangue pela veia coccígea, por meio de agulhas individuais e tubos com vácuo sem anticoagulante. Após a coleta, o material biológico foi encaminhado no interior de caixas de isopor com gelo ao Laboratório de Saúde Única da Universidade Federal da Fronteira Sul, Campus Realeza/PR, onde o soro foi submetido à técnica de ensaio imunoenzimático indireto (ELISA) para detecção de anticorpos IgG anti-T. gondii, utilizando a diluição de 1:200. Foi detectada uma prevalência de 67.8\% propriedades positivas e 55\% de animais reagentes. Os resultados são preocupantes, pois além de apresentar prevalência superior aos levantamentos regionais, diversos estudos indicam a ocorrência de taquizoítas de T. gondii no leite bovino, caracterizando um risco à saúde pública. Para controlar e prevenir a presença do patógeno nas propriedades, torna-se necessária a conscientização dos produtores de leite para evitar o acesso de felinos aos bovinos, locais de alimentação, pastagens e fontes de água desses animais, além do correto tratamento do leite ingeridos pelos felinos e, principalmente, pelos humanos. 